\title{
The (Un)Sustainability of Higher Education Institutions in Jordan
}

\author{
Sumaya bint El Hassan ${ }^{1,2 *}$, Kyle E. Cordova ${ }^{1,3 *}$, Ghaith Rabadi ${ }^{2,4 *}$ and \\ Wejdan Abu Elhaija ${ }^{1,2 *}$
}

${ }^{1}$ Royal Scientific Society, Amman, Jordan, ${ }^{2}$ Princess Sumaya University for Technology, Amman, Jordan, ${ }^{3}$ Advanced Research Centre, Royal Scientific Society, Amman, Jordan, ${ }^{4}$ Department of Engineering Management and Systems Engineering, Old Dominion University, Norfolk, VA, United States

OPEN ACCESS

Edited by:

Victoria Hurth,

University of Cambridge,

United Kingdom

Reviewed by:

Alison Julia Katherine Green,

Scientists Warning Foundation,

United States

Charlie Gardner,

University of Kent, United Kingdom

*Correspondence:

Sumaya bint El Hassan

president.office@rss.jo

Kyle E. Cordova

kyle.cordova@rss.jo

Ghaith Rabadi

grabadi@odu.edu

Wejdan Abu Elhaija

elhaija@psut.edu.jo

Specialty section:

This article was submitted to

Sustainable Organizations,

a section of the journal

Frontiers in Sustainability

Received: 15 January 2021

Accepted: 24 June 2021

Published: 16 July 2021

Citation:

Hassan SbE, Cordova KE, Rabadi G

and Abu Elhaija W (2021) The

(Un)Sustainability of Higher Education Institutions in Jordan.

Front. Sustain. 2:653992.

doi: 10.3389/frsus.2021.653992
Higher education in Jordan has been tied closely to the state-building process in the century since the modern Hashemite state's foundation in 1921, with its explicit purpose being to educate and train high volumes of students who are competent and capable to serve as contributors to the state's development. Though this purpose has largely been successful to date, it is becoming increasingly clear that more is needed than simply issuing degrees. In an increasingly globalized world, it is necessary to educate those who can contribute to future research arenas and labor markets over which a single state has limited control. Within this perspective, we detail the evolved societal position that higher education institutions in Jordan occupy and how that position has made such institutions a liability in the nation's continued sustainable development. It is important to emphasize that we do not address here classical sustainability issues, but rather focus on more fundamental and culturally-relevant issues pertaining to the survivability of universities in Jordan upon which more global sustainability views and solutions can be predicated. Specifically, we outline the unsustainability of impersonal, inefficient and ineffective infrastructure, centralization of policies and academic practices, lack of autonomy and/or self-governance, considerable financial dependence on the state, and a general hesitation for higher education institutions to seek boldly societal and economic impact beyond the simple production of graduates. To counter this unsustainability, we propose a three-pronged approach that can help catalyze the re-imagining of Jordan's higher education institutions so that they become maximally effective contributors to the state's future sustainable development. Our proposed approach is based on (i) internally decentralizing higher education institutions to enable greater autonomy and academic freedom, (ii) re-purposing these institutions to become more student-centric, and (iii) embracing diversity and academic community recognition. Finally, it is the intention of this perspective to highlight not only those challenges facing higher education institutions in Jordan, but also to present clearly the necessary and practical steps that institutions themselves may take immediately to ensure their relevance in, and impact on, modern society.

Keywords: higher education, university, developing countries, Jordan, Middle East and North Africa region, state-building, sustainable development 


\section{INTRODUCTION}

It is a truth almost universally acknowledged that the greatest resource of any nation is its people, and that future prosperity and sustainability lies in unlocking that peoples' innovative capacity to explore, discover and create. This is particularly true for a developing country with scant natural resources such as Jordan. Though the region in which present-day Jordan is located has been at the center of human conversations on innovation and the application of knowledge for thousands of years, the modern state of Jordan has reached a point where critical assessment and reform of its higher education institutions is vital, to ensure that innovation, scientific output, and sustainable solutions spring forth for current and future generations. This fresh, critical look is of the utmost urgency as Jordan, for better or for worse, very immediately and acutely embodies many of the growing global challenges that demand sustainable solutions. The problems Jordan faces today will be all the world's tomorrow, particularly in cross-cutting issues such as water, migration and social responsibility for justice and fairness in the allocation of dwindling resources (Whitman, 2019).

We believe that we are not alone in thinking that one must look back in order to look forward, for it is in the context of searching for that fresh perspective that an economical review of how we arrived at the current state of higher education is necessary. Put simply, higher education in Jordan does not have a long and storied history, but it does have all of the ingredients to create one, not least those ancient traditions of managing scant resources and innovating in harmony with the natural environment, and institutionally supporting the unlocking and education of scientific and artistic talent in the Islamic Golden Age. However, a significant hiatus of stagnation and marginalization has unquestionably obscured past achievements. Thus, the developmental timeline of modern higher education in Jordan may be categorized into four distinct phases (Mazawi, 2005; Buckner, 2011; Adely et al., 2019): (i) Creation of vocational training institutes in the 1950s to prepare students for teaching positions at compulsory school levels; (ii) Establishment of the first 4-year-degree national university, the University of Jordan, in 1961 to meet society's growing demands for further educational opportunities yielding more advanced skillsets; (iii) Expansion of the public university system in the 1980s to continue meeting rising demands by providing educational services to a larger citizenry in diverse geographic areas; and (iv) Proliferation of private and public universities starting in the 1990s to capitalize on a thirst for upward social mobility through education.

The underlying driving force for this modern development was, and continues to be, the state, which has viewed higher education as a tool for training high volumes of students to be competent and capable members of society who serve the state's historically largely centrally-planned economic development. Though not without benefits, this driving strategy does come with consequences. Due to the speed with which expansion and proliferation occurred, most public university campuses in Jordan were poorly planned resulting in impersonal, inefficient, and disconnected buildings that lack any expected sense of a communal, let alone intellectual, environment to be found. Indeed, this leaves most campuses feeling transactional and, to a certain degree, many have evolved to function as such. Furthermore, because the development of higher education has been so closely tied to the process of state-building, centralization of policies and academic practices have yielded public universities that lack distinct character or, even, specialization. Jordan's government has acknowledged this as a challenge and, as of 2018, has legally recognized both public and private universities as administratively, financially, and academically independentan action intended to enable universities to evolve organically to meet new market demands. However, at present, these laws exist only on paper with universities having yet to put them into practice. By and large, the same by-laws, policies, educational offerings, curricula, student services, and educational outputs can still be found at each of Jordan's 10 public universities.

To be clear, this is not to blame those universities for inaction. Rather, this reluctance to change is born out of historical hesitation to practice autonomy due to ministerial restrictions on self-governance that have held sway as a result of universities' significant financial dependence on the state. With a total debt of more than $\$ 150$ million held by Jordan's public universities (2019) and a yearly increasing budget deficit, it is expected that these universities' financial dependence on the state will continue for the foreseeable future (Jordan Times, 2019). But Jordan's public universities do have a semi-independent outlet to right their economic situation with the hopes of gaining increased autonomy in the future-their boards of trustees. Unfortunately, though, these boards have historically been underutilized and, thus, have failed to admit their responsibility in actively engaging in fundraising efforts. Public universities' primary source of nonstate funding comes from tuition fees, which has forced their focus to increasing admission numbers to cover their educational and operational costs. Increased admission of less-qualified students to what are known as "parallel programs" has come at the expense of delivering quality education and has diverted faculty away from research. Although the increasing intake at private universities has reduced the enrollment burden on public universities, it remains clear that the short-term budgetary requirements, or even short-sighted profit goals, of public and private universities have left no incentive to invest in quality of education or innovation. However, there are institutional bright spots, most notably, Princess Sumaya University for Technology (PSUT), that have managed to become financially more sustainable while not sacrificing quality education, as manifested by job placement rates of graduates. PSUT is a nonprofit university that has built a solid reputation on offering specialized technology and engineering programs that meet national and regional market demands. Though it has found a way to continuously modernize its educational offerings and has outlined its goal to evolve into a research institution, like other universities in Jordan, PSUT still largely depends on tuition revenues to support its operations. The long-term sustainability of tuition-based models will always be more susceptible to factors beyond an institution's control if they are not supported by other revenue sources such as research and development, innovation, and entrepreneurship. Nevertheless, all of these issues have been 
critically reviewed, dissected, and discussed in the literature, with a broad consensus emerging that nothing short of complete systemic transformational change is necessary for Jordan's higher education institutions to maintain their prominent societal position, and therefore, to have a meaningful impact on social and economic development in the coming decades (Badran et al., 2019, 2020; Rabadi, 2020; Shirazi, 2020; Zabalawi et al., 2020).

Although this is the general consensus, both in the literature and anecdotally from Jordanian faculty members and other stakeholders, in practical terms, this transformation may not happen quickly. In a state that faces regular and acute economic, social, and (geo)political development challenges, decision-making is likely to remain reactionary and myopic, while those who champion systemic transformational change will inevitably be overwhelmed by political exigencies that may not countenance the transformational change that, to many observers appears both essential and straightforward.

For the sake of simplicity, it is important to point out that a critical mass of decision-makers in Jordan has yet to recognize that the reality and requirements of education are no longer confined by state borders as was the case when first being developed in the early decades of the centralized state-building process-and this is where the barrier to activation for change is at its strongest. Can we create sufficient awareness and appreciation of the fact that the role of higher education institutions has evolved to become producers of competent and capable graduates whose advanced skills are transferrable beyond any one particular society or state? Perhaps wider acknowledgment of this could be the first step in launching a fifth phase of higher education development in Jordan. In support of this, can we explore concrete, practical initiatives that individual higher education institutions in Jordan can implement immediately that would yield maximum impact for sustainable progress, both in terms of human development and the support of a culture of sustainable economic and social development, without overly upsetting the existing higher education system that is so reluctant to change? Although a workable framework for answering these questions does not yet exist in Jordan, our short answer to each would be "yes." As detailed below, we propose several approaches supported by specific ideas and activities that universities could immediately start exploring without having to seek approval or permission from the relevant educational authorities. It is our belief that the following threepronged approach can help catalyze the re-imagining of Jordan's higher education institutions so that they become maximally effective contributors to the state's sustainable development and retain their established competitiveness on the regional and international levels. To be clear, we recognize that this approach is not necessarily ground-breaking in its novelty, but if properly followed, its impact would be felt across the country in meaningful ways. Accordingly, our proposed approach is as follows:

(i) Internal decentralization to enable greater autonomy and academic freedom:
It has become clear that, in Jordan, centralization at the national level begets greater centralization at the individual university level. This is wasting potential and obstructing the achievement of sustainable progress. Hierarchical modes of administration are outdated, slow, and ineffective. In practice, university presidents retain central authority with consecutively lower branches of administration (i.e., vice presidents, deans, and department heads) carrying out the duties assigned by those above them. In order to realize effective, dynamic institutions, decentralization of this authority across academic units should be of the highest priority. This makes intuitive sense, because in reality, those academic units are filled with topical experts who are the most capable on campus for planning and responding to the shifting tides of their respective disciplines. Indeed, is any university president truly capable of understanding the complexities of the differing needs that arise from all of the schools, departments, and programs that fall under their institution's educational banner? In a similar vein, the time spent by high-level administrators on lowerlevel tasks limits their availability to pursue larger and more impactful initiatives for the institution they serve. The role of the president, with support from other high-level administrators, should be to focus on setting the vision of the institution at large, establishing a collective strategic plan to realize that vision, and then guiding, governing, and implementing that plan by consensus with the deans and department heads (Batarseh, 2014). Finally, universities must reach out and practically engage with their boards of trustees as any serious attempts to realize a decentralized, efficient administrative framework will require taking and implementing bold decisions such as decentralizing budgets, managing human resources, imposing quality assurance programs and responsibilities, more targeted scholar and staff recruitment, as well as providing faculty and middle management greater freedom in decision-making. Afterall, responsibility with no authority is meaningless.

(ii) Re-purpose higher education institutions to be studentcentric:

When looking to re-purpose higher education institutions in Jordan to meet the societal demands of the future, it is important to begin by re-assessing the educational contract that exists between student and institution. Does the university effectively create a conducive environment for student learning and human growth? Do effective student services exist? Can a vision to make the institution an exemplar of sustainability, with students as its budding champions, seek to have a lasting impact on processes and practices in wider society?

Though the answers to these questions can be complex and nuanced, there is a lot that can be achieved from a high-level perspective. As a result of rapid growth and expansion, campus planning and university architecture in Jordan have resulted in largely impersonal environments and buildings that are not environmentally sustainable. But it does not have to remain this way. Universities can easily identify buildings and facilities that have become obsolete in order to re-allocate them for sustainable use by students (Winks et al., 2020). All university campuses in 
Jordan are ripe for outfitting with renewable sources of energy. Several universities, most notably Jordan University of Science and Technology, Hashemite University and the University of Petra, already power their campuses from solar panels resulting in close to zero energy bills (Qdais et al., 2019). In the digital age, libraries for example no longer require stacks of book shelves. It would be in the students' interests to repurpose such capacity into learning commons-spaces that offer high-tech collaborative work rooms, individual study areas, electronic equipment, and other free-to-use information technology. The impact of such a strategy may be taken for granted in other parts of the world, but in Jordan this has yet to be done.

It is also important to emphasize that students' needs extend beyond educational services. The university should be experienced by students as a community and mechanisms should be created to facilitate the growth of meaningful connections with peers as a vital support to personal growth (Beckers et al., 2016). Universities can enable this through the explicit creation of "student hubs" that operate with significantly extended hours. The "student hub" is a facility that provides large open spaces for students to engage with each other, offers diverse dining options, and supplies additional high-tech collaborative workspaces. Everything from job recruitment and a campus bookstore, to social and professional club activities can be held in this space. Indeed, most universities already have a starting point for realizing this "student hub"-the central cafeteriawhich naturally invites and facilitates the congregation of the student body.

Aside from creating a physical infrastructure that is studentcentered and community-focused, universities should also reassess the extracurricular services they provide to their student body to maximize academic success. For example, some private universities in Jordan have already established mentorship and guidance programs for incoming undergraduates. These should be celebrated, championed, and strengthened with further financial and administrative support, and expanded to public universities. A career management office that advises students on their professional career before and after graduation, and connects the universities with employers, can have a tremendous impact on the employability, placement and clarity of decision-making of graduates. Furthermore, the creation of new educational approaches that do not require ministerial approval should be explored. These include service-learning modules and/or service-learning course credits, paying greater attention to, investing in and deploying more virtual learning courses and resources. Additionally, formalizing internship programs during intersessions gives graduates richer experiences and better chances of employment. A good example is German Jordanian University, which requires every undergraduate student to spend one semester abroad at one of Germany's higher education institutions and a second semester interning with industry. It is true that governmental restrictions will always be present, but with a bit of creative thinking and institutional will-power, higher education institutions in Jordan can make a substantial impact on their student body by re-balancing the dynamic with new activities that are student-centric. (iii) Embrace diversity and academic community recognition:

Diversity yields novel, independent ways of thinking and ignites creative collaboration. As with any system of higher education in the world, Jordan's would benefit from a greater diversity of talent-diversity with respect to nationality, race, gender and background (bint El Hassan, 2020). This must happen from the top down. University presidents and high-level administrators in Jordan have been predominantly educated in the United States and Europe. It is interesting that although they have witnessed how autonomy, decentralization and academic freedom in higher education can lead to innovation, their lenses narrow after returning to Jordan and spending the majority of their professional life within that system. It is therefore highly probable that diversifying leadership via the recruitment of foreign or diaspora administrators and scientists from abroad marks an essential step toward effecting change and infusing higher education institutions in Jordan with new ideas and practices. This concept also extends to faculty members and the student body. Aside from bringing different experiences and ways of thinking to the table, diversifying faculty members will yield a presence on campuses that can disrupt conventional ways of pursuing education in Jordan. These faculty members will yield new educational philosophies, provide students with access to values and thought processes that are perhaps different, and expand the standard worldview of their students. Diversification of the faculty population should also be broadened to include the creation of senior lecturer and/or adjunct faculty positions for those accomplished industry leaders that are keen on engaging the youth. Although conservative academia in Jordan may reject the notion that non-tenure track faculty has a place in the university classroom, they must recognize that many subjects (e.g., entrepreneurship, business management, data science) are often best taught by the practitioner rather than the academic. It is also true that utilizing senior lecturers and/or adjunct faculty from industry to teach semester-long courses provides real-life experience and value to students. However, if recruiting and hiring foreign, diaspora, or industryderived adjunct faculty proves too expensive or bureaucratically challenging, then universities may also create a robust visiting scholar program. Such a program already exists in an elementary form in Jordan through a sabbatical system, but real brain-gain and diversification of talent on campuses will only happen if the visiting scholar program expands its reach beyond national or regional borders to include scholars from the Far East, Africa, and Latin America.

The final ingredient to consider when re-purposing universities in Jordan is a recognition of the wider university community. Good work far too often goes unseen and unrewarded in the existing incentive systems. In fact, these incentive systems are often viewed and indeed function as an exercise of rights rather than recognition and, thus, need to be re-purposed so that they operate on a merit basis and convey a higher degree of selectivity, independence and prestige. For example, scholarships for students could be transformed into a tiered system with those most-deserving from a merit perspective receiving a "named" scholarship, which inevitably instills a sense 
of prestige. Similarly, named professorship programs could be created for those faculty that excel in research and/or teaching. Upon appointment to a named professorship, faculty members may receive a fixed increase in salary, reprieve from teaching, and small seed funding for further research or teaching activities.

To attract the international community, endowed chair positions may also be created. Although these positions typically require a sustainable source of additional funding, it is certain that any investment would prove worthwhile for any university with foresight. Such positions attract renowned scholars who view these positions as academically prestigious and who also appreciate the advantages of the liberty that is provided to them to pursue research programs using the in-kind support and moderate funding that comes with such positions. Endowed chair programs can also be supported by international organizations with an interest in elevating the research capacity of countries like Jordan. This is not just wishful thinking, in fact, the British Academy and the Royal Scientific Society partnered in 2020 to endow the El Hassan bin Talal Research Chair for Sustainability, Jordan's first research chair in the social sciences and humanities (Royal Scientific Society, 2020).

\section{CONCLUSION}

The key resource for sustainable development in any country is human talent: Talent drives innovation; innovation leads to new enterprise creation; and new enterprises can generate highvalue employment that yields products, services, solutions, sales, exports, and financial returns. The challenge for Jordan has always been, and will continue to be, how to create the best possible structures to unlock and empower that talent. Higher education has historically been the primary chosen instrument and, in principle, this should be lauded. However, the guardians of this primary instrument for talent cultivation also have a responsibility to continuously adapt to: the shifting needs of the state, the economy and the environment; the desire for the state's

\section{REFERENCES}

Adely, F., Haddad, A., Al-Husban, H., and Al-Khoshman, A. (2019). Getting in and getting through: navigating higher education in Jordan. Comp. Ed. Rev. 63:1. doi: $10.1086 / 701127$

Badran, A., Baydoun, E., and Hillman, J. R. (2019). Universities in Arab Countries: An Urgent Need for Change. London: Springer, Cham.

Badran, A., Baydoun, E., and Hillman, J. R. (2020). Higher Education in the Arab World. London: Springer, Cham.

Batarseh, I. (2014). Reflections-a personal perspective on Jordanian higher education. Lead. Gov. Higher Ed. 4, 1-16.

Beckers, R., van der Voordt, T., and Dewulf, G. (2016). Learning preferences of higher education students. Build. Environ. 104, 243-252. doi: 10.1016/j.buildenv.2016.05.013

bint El Hassan, S. (2020). Arab women in science. Science 368:113. doi: $10.1126 /$ science.abc0631

Buckner, E. (2011). The role of higher education in the Arab state and society: historical legacies and recent reform patterns. J. Comp. Int. Higher Ed. 3, 21-26. Available online at: https://www.ojed.org/index.php/jcihe/article/view/809

Jordan Times (2019). Government Allocates JD18m to Cover Universities' Debts, and Budget Deficits. Available online at: http://www.jordantimes.com/news/ people to flourish in a land of finite resources; and the evolving challenges and demands of the global market. Unfortunately, this is where universities in Jordan have fallen short; their modi operandi are all-to-often outdated and unsustainable, due to factors that are mainly outside of their control. However, it is not all doom and gloom: Universities in Jordan do have the ability to take a fresh look within and to pursue internal activities and initiatives that are both rewarding and easily executed, including, but not limited to, internal decentralization, creation of student-centric environmentally-friendly campuses and activities, and diversification, and recognition and reward for the academic community.

\section{DATA AVAILABILITY STATEMENT}

The original contributions presented in the study are included in the article/supplementary material, further inquiries can be directed to the corresponding author/s.

\section{AUTHOR CONTRIBUTIONS}

All authors contributed equally to the conception of the idea and writing of the manuscript.

\section{FUNDING}

Financial support was generously provided by the Royal Scientific Society and Princess Sumaya University for Technology.

\section{ACKNOWLEDGMENTS}

We are grateful to Prof. Issa Batarseh (University of Central Florida), Mr. Conor de Lion (Royal Scientific Society), and Dr. Mazen Madanat (Royal Scientific Society) for their valuable feedback and discussions. local/government-allocates-jd $18 \mathrm{~m}$-cover-universities\%E2\%80\%99-debtsbudget-deficits (accessed June 15, 2021).

Mazawi, A. E. (2005). "Contrasting perspectives on higher education in the Arab states," in Higher Education: Handbook of Theory and Research, ed J. Smart (London: Springer), 133-189.

Qdais, H. A., Saadeh, O., Al-Widyan, M., Al-Tal, R., and Abu-Dalo, M. (2019). Environmental sustainability features in large university campuses: Jordan University of Science and Technology (JUST) as a model of green university. Int. J. Sustain. High. Educ. 20, 214-228. doi: 10.1108/IJSHE-06-20 18-0102

Rabadi, G. (2020). Can Jordan Become a Country of Innovation? Available online at: https://www.jordantimes.com/opinion/ghaith-rabadi/can-jordan-becomecountry-innovation (accessed June 15, 2021).

Royal Scientific Society (2020). Jordan's Royal Scientific Society and the British Academy announce new Jordan-UK El Hassan bin Talal Research Chair in Sustainability. Available online at: https://www.rss.jo/news/jordans-royalscientific-society-and-the- british-academy-announce-new-jordan-uk-elhassan-bin-talal-research-chair-in-sustainability/ (accessed June 15, 2021).

Shirazi, R. (2020). Being later, going with the flow, always doing more: the cruel optimism of higher education in Jordan. Int. J. Qual. Stud. Ed. 33, 293-310. doi: 10.1080/09518398.2019.1659444 
Whitman

E.

(2019).

20-23.

A

land doi:

without

water.

Nature

600-w

Winks, L., Green, N., and Dyer, S. (2020). Nurturing innovation and creativity in educational practice: principles for supporting faculty peer learning through campus design. Higher Ed. 80, 119-135. doi: 10.1007/s10734-019-00 468-3

Zabalawi, I., Kordahji, H., and Picone, C. (2020). "Reforming higher-education governance: a case study of Jordan," in Higher Education in the Arab World, eds A. Badran, E. Baydoun, and J. R. Hillman (London: Springer, Cham), 191-218.
Conflict of Interest: The authors declare that the research was conducted in the absence of any commercial or financial relationships that could be construed as a potential conflict of interest.

Copyright (c) 2021 Hassan, Cordova, Rabadi and Abu Elhaija. This is an open-access article distributed under the terms of the Creative Commons Attribution License (CC $B Y)$. The use, distribution or reproduction in other forums is permitted, provided the original author(s) and the copyright owner(s) are credited and that the original publication in this journal is cited, in accordance with accepted academic practice. No use, distribution or reproduction is permitted which does not comply with these terms. 